\title{
Doppler sonography of the corpus luteum during the oestrus cycle in dairy cows
}

\author{
GABRIELE MARINO, FLAVIA PRUITI CIARELLO, MICHELANGELO LA SPISA, \\ FRANCESCO MACRÌ, ALESSANDRA SFACTERIA, ANTONINA ZANGHÌ
}

Department of Veterinary Sciences, University of Messina, 98168 Messina, Italy

Marino G., Pruiti Ciarello F., La Spisa M., Macrì F., Sfacteria A., Zanghì A. Doppler sonography of the corpus luteum during the oestrus cycle in dairy cows

Summary

Doppler ultrasound has recently emerged as one of the main innovations in cattle practice and has mainly found application in the evaluation of luteal blood perfusion (LBF). LBF has been evaluated during different phases of the oestrous cycle, but the technique is poorly standardized. The aim of the study was to evaluate visual and quantitative changes of size of corpus luteum (CL) and LBF in dairy cattle during an oestrous cycle at 2 follicular waves using colour flow mode (CFM) and power flow mode (PFM) doppler ultrasound. Ten Friesian cows were selected and synchronized. The $C L$ was evaluated at 3/4-day intervals until the next oestrus onset. After identifying the spiral luteal artery entry at the base of the CL, multiple scans of the vertical plane at the maximum diameter of the $C L$ from the apex to the base were recorded in B-mode, CFM and PFM for each cow and session. An Esaote Mylab vet 30 gold was employed with the following setting: pulse repetition frequency 2.1 (CFM) or 2.8 (PFM), gain 70\%. The real area of CL (RACL) was calculated subtracting the area of the eventual inner cavity. The LBF was quantified off-line by means of a visual score and of an image analysis system (Digimizer 4.1). Student and Anova tests were used for statistical analysis. Data were presented as means and standard deviations. There were significant individual variations for the RACL and LBF when calculated in CFM. PFM minimized these variations, although, at day 15-16, it was also affected by individual factors $(p<0.01)$. The combined study of RACL and LBF during a 2-wave oestrous cycle distinguished 3 phases: a phase of CL formation (3-4 days) with LBF of $0.3 \pm 0.3 \mathrm{~cm}^{2}$ on a RACL of $3.1 \pm 0.9 \mathrm{~cm}^{2}$, a central phase (7-16 days) with $L B F$ of $0.7 \pm 0.4 \mathrm{~cm}^{2}$ on a RACL of $4.8 \pm 0.8 \mathrm{~cm}^{2}$ and a regression phase (19-20 days) with a minimum LBF of $0.1 \pm 0.1 \mathrm{~cm}^{2}$ in a $C L$ of $3.3 \pm 0.6 \mathrm{~cm}^{2}$. According to this study, there is no significant difference of LBF from 7 to 16 days of the oestrus cycle; although the RACL significantly changes in this period, the dimensional variations are too thin to be clinically appreciated. However, this study contributed to defining the values of RACL and LBF during a 2-wave oestrous cycle of dairy cattle.

Keywords: Friesian, ovary, blood flow, ultrasound

A reliable assessment of the age and functional status of the bovine corpus luteum (CL) is critical for different field applications such as early pregnancy diagnosis, use of prostaglandins in oestrus synchronizing programs, or selection of donors and recipients in embryo transfer programs. Under field conditions, the functional status of a CL is determined by transrectal palpation, which is based on the positive correlation between luteal size (LS) and progesterone (P4) levels $(12,15)$, although even experienced practitioners can make mistakes in CL manual assessment. Nowadays, ultrasound is the gold standard for a more reliable CL diagnosis, permitting evaluation of LS throughout the measure of the transverse diameter of the CL $(9,11$, $15)$. It has been debated whether LS is the most ap- propriate parameter for assessing the functional status of a $\operatorname{CL}(3,9,12,15,19)$. During the regression phase, large CLs may be already inactive $(9,15,18)$. P4 levels are strictly correlated with luteal blood flow (LBF) that can be assessed by transrectal colour Doppler sonography (1). In cows, LBF has been examined during short phases of the oestrous cycle $(1,10,14)$ and during an entire oestrus cycle (6). There are many differences among these studies regarding the enrolled animals, the ultrasound scanner and its setting, the kind of Doppler, the technique to capture representative scans of the CL and the system of evaluation of the blood flow. For this reason, data are not easily repeatable. Furthermore, the number of follicular waves affects the duration of the oestrus cycle in bovines. About $80 \%$ of dairy cows 
has two follicular waves and an interoestrus of about 20 days, while the remaining $20 \%$ has 3 follicular waves and an interoestrus of about 23 days; the timing of luteolysis is different and the luteal phase is 2-4 days longer in 3 follicular wave cows (5). The aim of the study was to evaluate by two alternative systems (image analysis and visual score) changes of LBF in the different phases of the oestrous cycle in cows with two waves of follicular growth dairy cattle by applying Colour and Power Doppler ultrasound.

\section{Material and methods}

The study was approved by the Ethics Committee of the Department of Veterinary Sciences of the University of Messina (reference number 010/2016). Friesian cows from a high standard farm in Ragusa, Italy, were selected for the following criteria: age (3-5 years), over 70 days post-partum, good reproductive anamnesis, body condition score greater than or equal to 3 , healthy, lack of abnormality and disease of the genital tract, anatomical conformation of uterus and ovaries (pelvic displacement), and docile temperament. Ultrasound and Doppler examination were performed using an Esaote My Lab Vet 30 Gold (Genoa, Italy) equipped with a 5-7.5 MHz endocavitary linear probe. Only cows with a CL larger than $2 \mathrm{~cm}$ in diameter and a dominant follicle over $8 \mathrm{~mm}$ were synchronized with a single administration of the synthetic prostaglandin F2alpha (cloprostenol $500 \mathrm{mcg}$ im, Estrotek, Fatro). The visual monitoring of the oestrous manifestations was performed twice a day until the onset of the standing oestrus. Only cows showing standing oestrus from 48 (day 0 ) to $72 \mathrm{~h}$ (day 1 ) after prostaglandin injection were enrolled. The ultrasound sessions started from day 4, when the newly formed CLs could be evaluated. The procedure was repeated at day $8,12,16$ and 20.
Furthermore, the follicular wave emergence at the $4^{\text {th }}$ day ( $1^{\text {st }}$ follicular wave) and at $12^{\text {th }}$ day ( $2^{\text {nd }}$ follicular wave) was recorded and the dominant follicle of the $2^{\text {nd }}$ follicular wave was followed until ovulation. The cows were restrained by means of self-tapping racks and at the same time palatable food was supplied. The Doppler scans were performed by slowly moving the transducer on the ovary surface, from the cranial to the caudal pole until identifying the luteal spiral artery and visualize the maximum transverse diameter of the CL, in order to scan a vertical plane including the apex and the basis of the CL (1). The transducer was kept at a distance of about $1-2 \mathrm{~cm}$ from the CL. The ultrasound setting for each session in colour flow mode (CFM) was: frequency $5.0 \mathrm{MHz}$, gain $70 \%$, pulse repetition frequency (PRF) $2.1 \mathrm{KHz}$, dynamic range, enhancement and density (PRC) 3-BA, persistence (PRS) 4, velocity $\pm 16 \mathrm{~m} / \mathrm{s}$; and in power flow mode (PFM): frequency $5.0 \mathrm{MHz}$, gain $70 \%$, PRF $2.8 \mathrm{KHz}$, PRC 3-BA, PRS 4. In absence of flash and blooming artefacts, at least 3 images were recorded for each session and for all the functions: B-mode, CFM and PFM. The real area of the CL (RACL) was calculated with the formula $\mathrm{RACL}=\Pi(\mathrm{D} / 2)^{2}-\Pi(\mathrm{d} / 2)^{2}$, where $\mathrm{D}$ was the diameter of the $C L$ and $d$ the diameter of the eventual inner cavity. The LBF was quantified off-line by means of a visual score and of an image analysis system (Digimizer 4.1) (Fig. 1). The LBF was expressed in $\mathrm{cm}^{2}$. A visual score developed for follicles (4) was also used, estimating the percentage of coloured luteal tissue respect to the complete circumference delimiting the CL (Fig. 2). The following grading was employed: 1 if less of $25 \%$; 2 if between 25 and 50\%; 3 if between 50 and $75 \%$; 4 if over $75 \%$. Each ultrasound session had an average duration of about 7 minutes and was performed from 9:30 to 11:30 am by the same operator. After verifying the normality of the data, the repeatability

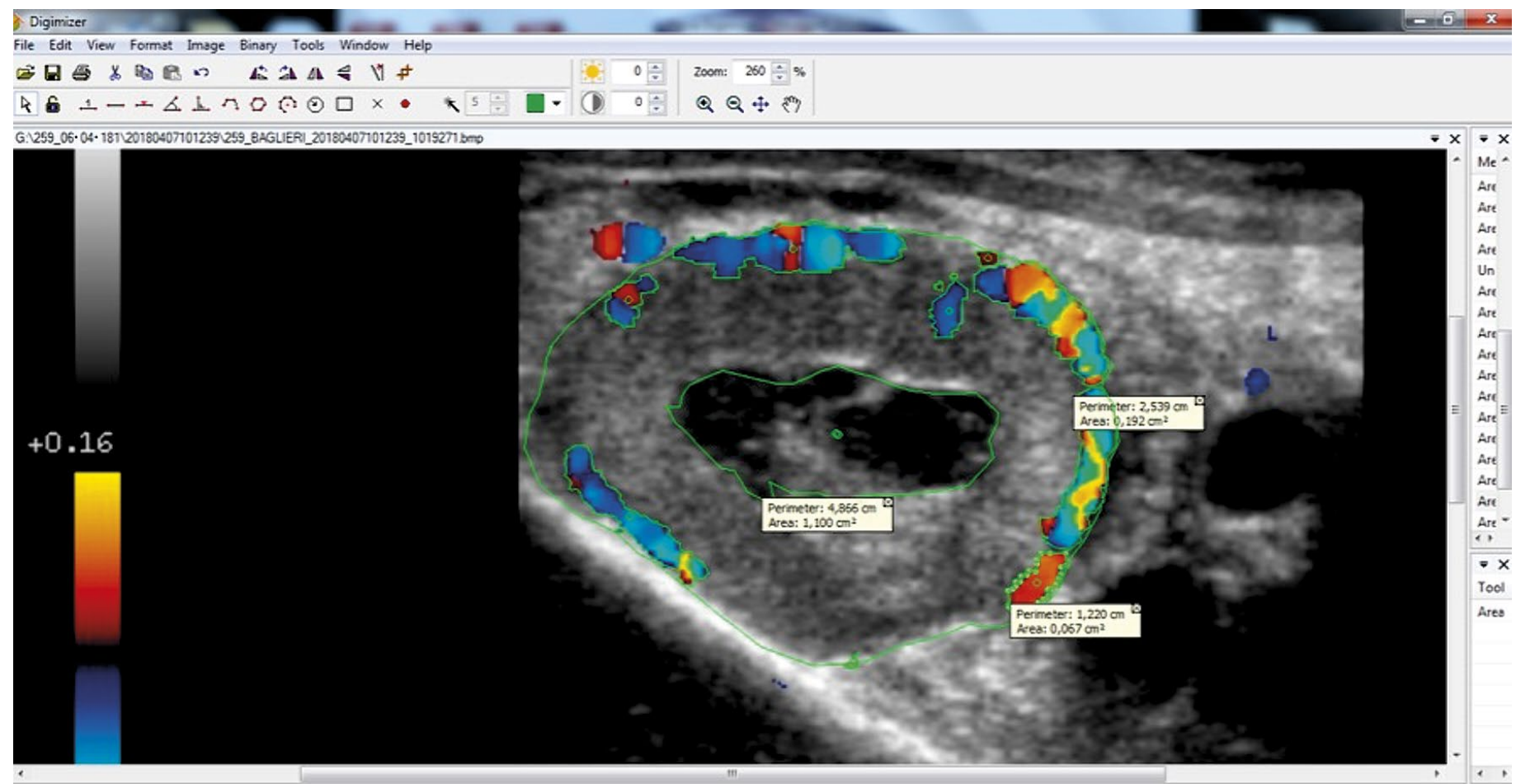

Fig. 1. Image analysis (Digimizer 4.0) for the calculation of the area of corpus luteum and inner cavity. Luteal blood flow area was obtained by the addiction of the coloured pixels inside the luteal parenchyma 

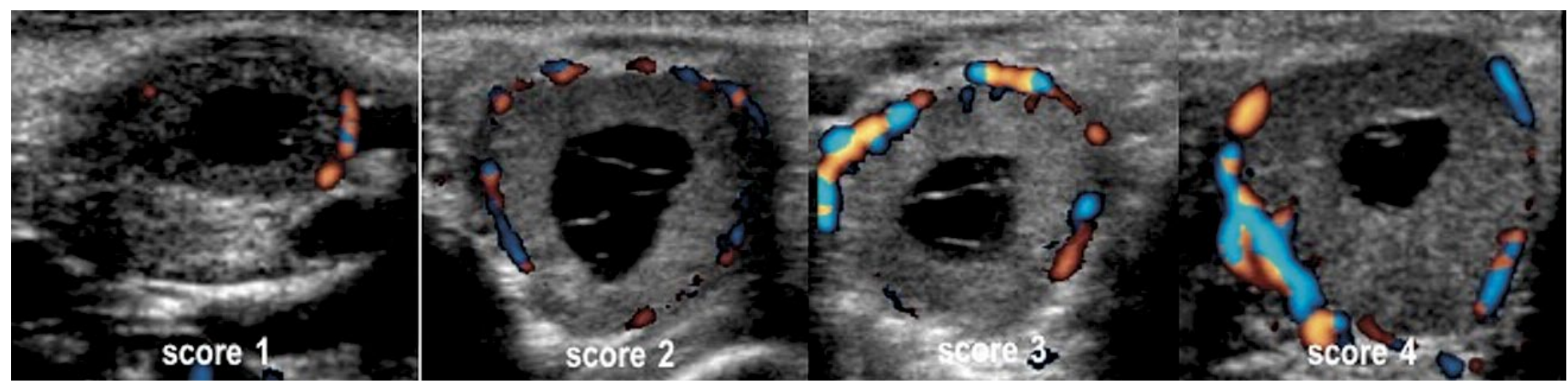

Fig. 2. Visual score was based on the percentage of coloured peripherical parenchyma of the corpus luteum. Score 1: less than $25 \%$. Score 2: from 25 to $50 \%$. Score 3 from 50 to $75 \%$. Score 4 more than $75 \%$

of the measurements was tested by a two-way Student test. A total of 548 scans were performed, 160 in B-mode, 209 in CFM and 179 in PFM with a mean of 3.2, 4.2 and 3.6 scans for session and cow. RACL and LBF were calculated for each scan. The probability of an erroneous capture of the CL and, consequently, measurement of RACL and LBF was 0.00 for B-mode, 0.01 for CFM and 0.01 for PFM. An Anova one-way was employed to exclude individual variability. The Student unpaired test was finally employed to compare the means for each detected parameter (RACL, LBF in CFM, PFM, visual score CFM, visual score PFM) in the days of the oestrus cycle. The significance was set at 0.05. The employed software was "goodcalculators".

\section{Results and discussion}

Starting from 30 enrolled cows, only 10 were admitted to the study showing the standing oestrus from 48 to 72 hours after the prostaglandin administration. A single CL was detected in all and monitored at days $4,8,12,16$, and 20 . The first follicular wave emergency was detectable at day 4 , a second one at day 12 . All the cows showed oestrus after 19-20 days, confirming a two follicular wave cycle. Comparing the measurements taken at same days in different animals, Anova test demonstrated a significant difference among cows in RACL measurement and in the coloured area of CL using CFM when calculated at days 3-4 and 15-16 $(\mathrm{P}=0.00)$. Using PFM, a significant difference was evident only at days 15-16. In order to analyse the effect of the day of the oestrus cycle data were grouped as mean and standard deviation (Tab. 1). Unpaired

Tab. 1. Data of the real area of corpus luteum (RACL), luteal blood flow (LBF) area calculated with Digimizer or visual score in colour (CFM) and power flow mode (PFM) in along two-wave oestrus cycles in Friesan cows

\begin{tabular}{|c|c|c|c|c|c|}
\hline \multirow{2}{*}{$\begin{array}{c}\text { Oestrus } \\
\text { cycle days }\end{array}$} & \multirow{2}{*}{ RACL cm ${ }^{2}$} & \multicolumn{2}{|c|}{ LBF area - Digimizer $\mathrm{cm}^{2}$} & \multicolumn{2}{|c|}{ LBF - visual score } \\
& & CFM & PFM & CFM & PFM \\
\hline $3-4$ & $3.1 \pm 0.9^{\mathrm{a}}$ & $0.3 \pm 0.3$ & $0.3 \pm 0.3$ & $1.3 \pm 0.7$ & $1.7 \pm 0.7^{\mathrm{e}}$ \\
\hline $7-8$ & $4.9 \pm 0.8$ & $0.8 \pm 0.3$ & $0.8 \pm 0.3^{\mathrm{c}}$ & $1.8 \pm 0.5$ & $2.1 \pm 0.5$ \\
$11-12$ & $5.3 \pm 0.7$ & $0.6 \pm 0.3^{\mathrm{b}}$ & $0.7 \pm 0.4^{\mathrm{c}}$ & $1.5 \pm 0.4^{\mathrm{d}}$ & $1.6 \pm 0.4^{\mathrm{e}}$ \\
$15-16$ & $4.6 \pm 1.1$ & $0.5 \pm 0.5^{\mathrm{b}}$ & $0.7 \pm 0.6^{\mathrm{c}}$ & $1.6 \pm 0.8^{\mathrm{d}}$ & $1.7 \pm 0.8^{\mathrm{e}}$ \\
$19-20$ & $3.3 \pm 0.6^{\mathrm{a}}$ & $0.1 \pm 0.1$ & $0.1 \pm 0.1$ & $1.0 \pm 1.0$ & $1.0 \pm 1.0^{\mathrm{e}}$ \\
\hline
\end{tabular}

Explanation: Data are compared within columns. The same letter (a, b, c, d, e) states for a not-significant difference $(p>0.05)$
t-Student test demonstrated a non-significant difference between RACL calculated at days 3-4 and 19-20. The coloured area was not significantly different from 11 to 16 days in CFM using the image analysis or the visual score, from 7 to 16 days in PFM using the image analysis, while visual score in PFM showed a significant peak of flux at days 7-8. The combined study of RACL and LBF calculated in PFM with an image analyser distinguished 3 phases: a phase of CL formation (3-4 days) with LBF of $0.3 \pm 0.3 \mathrm{~cm}^{2}$ on a RACL of $3.1 \pm 0.9 \mathrm{~cm}^{2}$, a central phase (7-16 days) with LBF of $0.7 \pm 0.4 \mathrm{~cm}^{2}$ on a RACL of $4.8 \pm 0.8 \mathrm{~cm}^{2}$ and a regression phase (19-20 days) with a minimum LBF of $0.1 \pm 0.1 \mathrm{~cm}^{2}$ in a RACL of $3.3 \pm 0.6 \mathrm{~cm}^{2}$.

The aim of this paper was to characterize the blood perfusion in the bovine CL during the oestrus cycle. In order to standardize the findings only dairy cows with two follicular waves were selected. Doppler ultrasound is a technique that requires performing equipment and a minimal training of operators. The setting of the machine and the approach of the examined organ have to prevent artefacts. CL has a quite spherical appearance, but vascularization is not symmetrical and homogenously displaced in the parenchyma. The spiral artery reaches the base of the CL and branches in some capsular arterioles that tend to reach the apex of the CL. Lobular vessels are less evident with Doppler resolution unless managing the setting. The identification of the spiral artery is facilitated by the orientation of the probe along the longitudinal axis of the ovary, taking as a reference point the mesovary and the proper ligament of the ovary (7). The area of the CL with the maximum diameter including the apex and the base, identified by the spiral artery entry, was used in this study according to previous study (1) and it is extremely important for the standardization of the measurements. In our study, the PRF was set to a value of $2.1 \mathrm{KHz}$ for CFM and 2.8 KHz for PFM. However, PRF settings of $1.4 \mathrm{KHz}$ have been employed $(8,14)$. The evaluation of luteal perfusion may be done directly in the desktop or off line after freezing significant screen shots or films. 
In field applications, a visual scoring is probably the only possible kind of evaluation. In our study and with our settings, having only peripherical Doppler signals of CLs, a visual scoring designed for follicles was thought to be appropriate (4). In experimental studies, a quantitative evaluation of the coloured area or pixels may be done with different and equivalent image analysis software. If standardized, the Doppler technique applied to bovine $\mathrm{CL}$ is rapid, safe, powerful and repeatable. In order to give minimal discomfort to the animals, as requested by the ethics Committee, the procedure was repeated with 4 day intervals. LBF and RACL showed individual variations in the growth and regression phases of CLs. PFM minimized such variations on the growth phase, but not at day 15-16. At this time, PGF2alpha signal causes a temporary (about 2 hours) increase of vascularization followed by a rapid decline $(10,16)$. This phenomenon together with an individual timing of onset of luteolysis may explain the significant individual variation of LBF at 15-16 days. PFM is a technique that displays the strength of the Doppler signal in colour and it is not dependent by the speed and direction of fluxes. It is particularly useful for small vessels with low-velocity flow. The final analysis of RACL and LBF variations during the two-wave oestrus cycle did not allow a unique interpretation of results. A visual score in CFM, but not in PFM, seems to be able to differentiate the non-functional CL (3-4 or 19-20 days) from the functional CL (7-16 days). Quantitative evaluation of LBF in PFM or CFM confirmed this screening ability. The main clinical application of such a finding is the early pregnancy diagnosis in cows and heifers, where non-functional CL with minimal or no flux are indicative of non-pregnant animals (2). On the other hand, it is not possible to differentiate, using Doppler, a CL from 7 to 16 days and, consequently, it is not possible to predict the phase of the oestrus cycle using LBF evaluation. Although the RACL significantly changes in this period, the dimensional variations are too thin to be clinically appreciated. However, in this paper an LBF area of $0.7 \pm 0.4 \mathrm{~cm}^{2}$ in PFM was found in these functioning CLs. When LBF is over this value a good progesterone producing CL may be suspected and consequently managed. Probably cows bearing these CLs are good candidates to become embryo recipients or to come into PGF2 alpha protocols of oestrus synchronization (13). When LBF is under this value a mild $\mathrm{P} 4$ producing CL may suggest cows that are more suitable to $\mathrm{GnRH}$ or gonadotrophin treatments for synchronization and superovulation, for the less inhibitory effect on the new follicular wave emergence (17). In conclusion, this study contributed to defining the values of RACL and LBF during a two-wave oestrous cycle of dairy cattle.

\section{References}

1. Acosta T. J., Yoshizawa N., Ohtani M., Miyamoto A.: Local changes in blood flow within the early and midcycle corpus luteum after prostaglandin $\mathrm{F}$ ( 2 alpha) injection in the cow. Biol. Reprod. 2002, 6, 651-658.

2. Andrade J. P. N., Andrade F. S., Guerson Y. B., Domingues R. R., GomezLeón V. E., Cunha T. O., Jacob J. C. F., Sales J. N., Martins J. P. N., Mello M. R. B.: Early pregnancy diagnosis at 21 days post artificial insemination using corpus luteum vascular perfusion compared to corpus luteum diameter and/or echogenicity in Nelore heifers. Anim. Reprod. Sci. 2019, 209, 106-144.

3. Battocchio M., Gabai G., Mollo A., Veronesi M. C., Soldano F., Bono G., Cairoli F.: Agreement between ultrasonographic classification of the CL and plasma progesterone concentration in dairy cows. Theriogenology 1999, 51, 1059-1069.

4. Bhal P. S., Pugh N. D., Chui D. K., Gregory L., Walker S. M., Sha R. W.: The use of transvaginal power Doppler ultrasonography to evaluate the relationship between perifollicular vascularity and outcome in in-vitro fertilization treatment cycles. Hum. Reprod. 1999, 14, 939-945.

5. Ginther O. J., Knopf L., Kastelic J. P.: Temporal associations among ovarian events in cattle during oestrous cycles with two and three follicular waves. J. Reprod. Fertil. 1989, 87, 223-230.

6.Herzog K., Brockhan-Ludemann M., Kaske M., Beindorff N., Paul V., Niemann H., Bollwein $H$.: Luteal blood flow is a more appropriate indicator for luteal function during the bovine estrous cycle than luteal size. Theriogenology 2010, 73, 691-697.

7. Kanazawa T., Seki M., Ishiyama K., Araseki M., Izaike Y., Takahashi T. Administration of gonadotropin-releasing hormone agonist on Day 5 increases luteal blood flow and improves pregnancy prediction accuracy on Day 14 in recipient Holstein cows. J. Reprod. Dev. 2017, 63, 389-399.

8. Kanazawa T., Seki M., Ishiyama K., Kubo T., Kaneda Y., Sakaguchi M., Izaike Y., Takahashi T.: Pregnancy prediction on the day of embryo transfer (Day 7) and Day 14 by measuring luteal blood flow in dairy cows. Theriogenology 2016, 30, 1-9.

9. Kastelic J. P., Pierson R. A., Ginther O. J.: Ultrasonic morphology of corpora lutea and central luteal cavities during the estrous cycle and early pregnancy in heifers. Theriogenology 1990, 34, 487-498.

10. Miyamoto A., Shirasuna K., Wijayagunawardane M. P., Watanabe S., Hayashi M., Yamamoto D., Matsui M., Acosta T. J.: Blood flow: a key regulatory component of corpus luteum function in the cow. Dom. Anim. Endocrinol. 2005, 29, 329-339.

11. Pierson R. A., Ginther O. J.: Ultrasonography of the bovine ovary. Theriogenology 1984, 21, 495-504.

12. Pieterse M. C., Taverne M. A., Kruip T. A., Willemse A. H.: Detection of corpora lutea and follicles in cows: a comparison of transvaginal ultrasonography and rectal palpation. Vet. Rec. 1990, 126, 552-554.

13. Pugliesi G., Dalmaso de Melo G., Silva J. B., Carvalhêdo A. S., Lopes E., de Siqueira Filho E., Silva L. A., Binelli M.: Use of color-Doppler ultrasonography for selection of recipients in timed-embryo transfer programs in beef cattle. Theriogenology 2019, 135, 73-79.

14. Pugliesi G., Oliveria M. L., Scolari S. C., Lopes E., Pinaffi F. V., Miagawa B. T., Paiva Y. N., Maio J. R., Nogueira G. P., Binelli M.: Corpus luteum development and function after supplementation of long-acting progesterone during the early luteal phase in beef cattle. Reprod. Domest. Anim. 2014, 49, 85-91.

15. Ribadu A. Y., Ward W. R., Dobson H.: Comparative evaluation of ovarian structures in cattle by palpation per rectum, ultrasonography and plasma progesterone concentration. Vet. Rec. 1994, 135, 452-457.

16. Shirasuna K., Asaoka H., Acosta T. J., Wijayagunawardane M. P., Matsui M., Ohtani M., Miyamoto A.: Endothelin-1 within the corpus luteum during spontaneous luteolysis in the cow: local interaction with prostaglandin F2alpha and angiotensin II. J. Cardiovasc. Pharmacol. 2004, 44 Suppl 1, 252-255.

17. Tamboora D., Kupin D., Sumande J.: Superovulation in cows: a relationship between progesterone secretion before ovulation and the quality of embryos. Anim. Reprod. Sci. 1985, 8, 327-334

18. Tom J. W., Pierson R. A., Adams G. P.: Quantitative echotexture analysis of bovine corpora lutea. Theriogenology 1998, 49, 1345-1352.

19. Veronesi M. C., Gabai G., Battocchio M., Mollo A., Soldano F., Bono G., Cairoli F.: Ultrasonographic appearance of tissue is a better indicator of CL function than CL diameter measurement in dairy cows. Theriogenology 2002, $58,61-68$.

Corresponding author: Gabriele Marino, BS, DVM, PhD, Associate professor at the Department of Veterinary Sciences, 98168 Messina, Italy; e-mail: marinog@unime.it 